\title{
The Different Perspective of Managerial and Operational Level toward Customer Relationship Management Practice in Thailand
}

\author{
Tanakorn Limsarun (Corresponding author) \\ School of Management, Shinawatra University \\ 197 Viphavadi-Rangsit Road Samsen Nai Phayathai Bangkok 10400, Thailand \\ Tel: 668-9303-9999Ｅ-mail: Limsarun@hotmail.com \\ Pacapol Anurit \\ School of Management, Shinawatra University \\ 197 Viphavadi-Rangsit Road Samsen Nai Phayathai Bangkok 10400, Thailand \\ Tel: 662-650-6012Ｅ-mail: Pacapol@siu.ac.th
}

\begin{abstract}
Nowadays, Customer Relationship Management (CRM) has become the important part of business due to the benefit of analyze sale opportunities, campaigns management, personalization to each individual customer, cross-selling and up-selling. Unfortunately, many research evidence shows that most of the companies fail to make their CRM effort to pay off. Thus success CRM is required co-operate from the management top down in the CRM installed companies but there is no commonly agreed frame study for the effective CRM's implementation and CRM's influential factors toward the managerial and operational perspective. Therefore this study aims to fulfill this gap and highlight the different influential factors. The finding has shown the perspective gap toward the CRM success factors, while each part of the organization has to take care for their role and responsibility in order to success in CRM practice.
\end{abstract}

Keywords: Customer Relationship Management Practice, Influential Factor, Information and Communication Technology (ICT), Customer Relationship Management Information Systems (CRM-IS). 


\section{Introduction}

Nowadays, Customer Relationship Management (CRM) has become the important part of business, especially large business organizations while the small and medium sized companies are increasing the interest due to the benefit of analyze sale opportunities, campaigns management, personalization to each individual customer, cross-selling and up-selling (Greenberg, 2010). CRM can also support the organization to increase in the level of customer relationships, customer satisfaction, efficiency, effectiveness of its internal processes and higher revenue (Valsecchi et al., 2007). The concept of CRM is not only another information tool, if the organization applied properly, CRM can yield an exceptional return in revenue and improve customer service (Nguyen et al., 2007). Support from the study of Kimiloglu and Zarali (2009) has shown the finding on 72 businesses in Turkey that the organization who success in adopt CRM practice in their organizations have the significantly improvement on speed, effectiveness, reliability of their business process, customer satisfaction, revenue, brand image, efficiently business process and technology utilization (Kimiloglu and Zarali, 2009).

With these advantages, the total worldwide Customer Relationship Management (CRM) software market reported by the AMR Research and Gartner had been exceeded to \$13 Billion (USD) in the year 2008 (Bull and Adam, 2010) and will likely to reach \$22 billion in the year 2012 with 36 percent growth rate (Greenberg, 2010).

Unfortunately over 1,700 companies worldwide have been surveyed, the results show that only $16.1 \%$ of the Customer Relationship Management practice companies are reporting that CRM system usage is resulting in increased revenues in the their companies while the majority of firms or $83.9 \%$ are underutilizing the CRM tools they have in place (Dickie, 2009). The most of CRM practice companies are significant invest in their effort and resources, fewer take the time to determine whether they are getting the optimal return on their CRM practice which included the strategic, technical, organizational and business process review, these are the cost-effective way to identify and resolve issues that may be the obstacle of both user adoption and payback from resources allocated (Goldenberg, 2010).

In Thailand, the National Statistical Office showed that there are only $20.7 \%$ of the total companies established in Thailand who gain benefit by adopt the Information and Communication Technology while $79.3 \%$ of the companies are lost or have the same revenue by adopt Information and Communication Technology (ICT), the important barriers of ICT practice in Thailand are expenditure too high, technology is too complicated, existing personal reluctant to use, lack of skills, difficult to recruit qualified personal and security concerns (National Statistical Office of Thailand, 2007). It was conforming to the study of Aruthari (2005) who study in Information Technology adoption by companies in Thailand showed the findings that, the barrier to adopt CRM practice consist of the following factors 
which are lacks of perceive benefit of CRM system, lack of adequate funding, lack of adequate personnel resource and resistant to new technology (Aruthari, 2005).

\section{Literature review}

\subsection{The benefits of success CRM Practice}

Thus, the companies who initiate a good Customer Relationship Management Practice will maximizing the potential of existing customers, acquiring new customers that are profitable or likely to have the potential and retaining customers who are profitable and enhance the firm performance (Boulding et al, 2005). Also increase the level of supports, leverages, expands the communications, captures and shares key customer information, creates visibility for the organization through sophisticated customer information analytic tools, supports business continuity and improves both up-selling and cross-selling (Ward, 2007). Support from the study of Aleric (2007) who has proved a higher competitiveness of Information and Communication Technology service providers in Croatia who practiced CRM compare to the other service providers who did not, the result shows the advantages of having a good CRM practice on a stronger demand from customers, increased service competitiveness, long-lasting relationship, unique and recognizable, higher client loyalty and success rate in fulfilling its mission.

\subsection{The influential factors toward the success of Customer Relationship Management}

Before implementing CRM, organization has to evaluate the fit of CRM in their organization, current CRM capabilities and good reason to implementing CRM, together with the good implementing strategy (Nguyen, Sherif \& Newby, 2007). However, CRM is a concept that requires suitable business process, effective system integration, evaluation process after implement Customer Relationship Management System (CRM Evaluation Process) (Zineldin, 2006) and CRM feedback which able to increases organization CRM's efficiency (Palsinghtoor, 2009), where the business processes which adapt to support CRM practice can enable the companies to increase the relationship between employee, customer and supplier by creating a good environment for operate business (Skrinja, Vuksic and Stemberger, 2008). At the same time, the study of Lorenzon and Pilotti (2008) on the 60 managers in both Italy and Netherlands medium to large size companies who have more than 100 employees shows the result from his survey that most of the managers believe the change management is the most critical strategy to initiative a good CRM project, it consist of clear understanding of the relationship with the customer, knowledge sharing and employee commitment respectively. Moreover focusing on the organization's cultural and practical requirements, the organization can more easily overcome employee's resistance to adopting new applications, without above factor, no CRM project can successfully implement, although the best CRM has been installed (Lorenzon \& Pilotti, 2008). The study of Yi-Te (2010) also support that change management is very important to the success of CRM implement. While technology factor is only some part of the project, people are the key to making with CRM success, while top management support should focus not only CRM system but also arrangement of the personal in order to increase level of the cross functional integration of process, people, operations and technology (Yi-Te, 2010). Support from the study of Palanisamy et al. (2010) has shown the 
finding on interview 183 samples of organizations in North America, that CRM performance, strategy, business process reengineering, management support and end user buy-in are the influential factor to CRM system acquisition. Therefore, CRM success is required the change in organizational normal business process to support the CRM system which design the path way to best practice, together with the high level of employees' commitment (Shum, Bove \& Auh, 2008), a clear CRM vision, support from the management in term of tangible and intangible resources to support Customer Relationship Management System (management support), co-operate within organization to use the Customer Relationship Management System (Employee Buy-In), suitable corporate culture and focus of user requirement, these are the success factors which can be applicable both large, medium and small sized of CRM installed companies (Xevelonakis, 2005; Doom, Milis, Poelmans \& Bloemen, 2010; Lambert, 2010). Moreover the finding form the study of Chang, Lie and Fan (2010) in 87 samples of top four real estate brokerage companies in Taiwan showed that employees' computer selfefficacy which increased by adequate support and training, can make the CRM user efficiently deal with the problem and increase their usage of CRM system. The study of Limsarun and Pacapol (2010) who studied in the CRM practice of ICT public listed companies in Thailand, has shown the finding on managerial perspectives that the executives believe individual level ability to use Customer Relationship Management System (computer self-efficacy), the different between believe, attitude and way to conduct job of Information Technology and Business Culture in Organization (IT and Business culture gap), Organization's perception toward the benefit and important of Customer Relationship Management System (organizational CRM mindset), and CRM Software Utilization are the influential factors to the success of CRM practice (Limsarun \& Pacapol, 2010).Supported from the research conducted by Raman, Wittmann and Rauseo (2006), the result of surveyed from 65 worldwide companies show that in the implementation stage, manager need to bring unit of the organization together in order to assist in specifying needs as well as better understanding of the business and technical requirement, the lack of team involvement can affected to the capable of delivering CRM utilization and the success of CRM practice. Moreover the selection of CRM application should be undertaken by a committee comprising representatives from all departments and top management that are stakeholders for the CRM implementation (Mukerjee, \& Singh, 2009). Also support from the study of Ifinedo (2008), 62 managements of 44 firms located in Finland and Estonia has agreed that the top management support and business vision are significant related to the level of CRM system success. Another support from the study of Dimitriadis and Stevens (2008) who suggested the effective CRM required the integrated perspective and coordination among all components which are strategy (a clear company's vision related CRM and adequate management commitment), organizational (align business process and customer-centric culture), employee's perception toward the benefit and important of Customer Relationship Management System (Employee's CRM Mindset) and level of information sharing, data security, integrated data, and quality data of Customer Relationship Management System (CRM System Utilization). The study of Chahal (2009) who studied in operational and analytical CRM of healthcare services in India has shown the finding that mindset change is the key to build the competitive interest in employees and make them understanding their role 
to increase loyalty and customer satisfaction. Support from the study of Pedron and Saccol (2009) suggest the concept to success in CRM practice, at the beginning organizations have to be oriented by CRM philosophy to make the organization's culture both create and support long term relationship with the customer, also with the qualified employees to serve client properly via the CRM tools. Then the organization need to concern on the CRM strategy which is the change in the organization structure, rewarding and evaluating staff system connected to CRM goal. The last step is to adapt the CRM technology which has to collaborative from multidisciplinary team (Pedron \& Saccol, 2009). The study from Mukerjee and Singh (2009) stated the strategic approach of CRM that can help in increasing the chances of successful CRM implementation which are CRM vision, CRM goal and CRM implementation. The study from Ranjan and Bhatnagar (2009) suggested the successful implementation of CRM in organization depends on employees' interest and ready to accept change to the new system, moreover new CRM system has to be flexibility, maintainable, reliable and consistent enough to support necessary change suggested by the management and organization. Moreover, Information Technology infrastructure has positive and significant relationship to the customer responsiveness which leads to the business advantage to the companies (Bhatt \& Emdad, 2010). While the study from Elmuti, Jia and Gray (2009) on the Customer Relationship Management strategic application and organizational effectiveness show the result from surveyed 500 financial service providers in the United States that $79 \%$ of the respondents agreed that the greatest barrier of CRM success comes from lack of leadership and management skill, while $64 \%$ of respondents agreed on poor data quality and inadequate data concerning their customer, competitors and markets, and 51\% of respondents reported on top management support respectively, Moreover, it is a clearly indicate that most of the organizations were less understanding of the requirements and benefits of CRM by different functional managers in the surveyed firm (Elmuti, Jia and Gray, 2009).

\section{Research Objectives}

Thus, the perspective of managerial and operational level towards the CRM influential factor is likely to differ according to the job title, roles in organization (Palanisamy et al., 2010) and style which influence to the organization performance (Richardson and Foong, 2004). Since, there is no commonly agreed framework for the effective CRM's implementation and CRM's influential factors (Lo, Stalcup \& Lee, 2010). The purpose of this study is to investigate and highlight the different perspective of managerial and operational toward the CRM practice in their organization At the same time, this research study would anticipate to yield useful significances as followings:

Firstly, to provide a guideline and highlight key success factors toward the managerial and operational level perspective of CRM practice companies.

Secondly, the finding of this paper could create a greater awareness on the perspective gap between managerial and operational level, since CRM success has to be initiated by the management top down (Xevelonakis, 2005). 
Thirdly, the finding of this paper could create a greater awareness on the advantages of the CRM practice and it could relate to many investment project, post-audit phase in general have been defected. We use CRM as a case study which likely to applicable for any industry.

\section{Research Method}

In order to find the perspective gap between managerial and operational level toward the CRM practice of CRM installed companies in Thailand, the primary data were collected by techniques including formal and informal interviews and direct observations by the researchers in order to uncover the informants perspective toward CRM practice in their organization, the qualitative approach was applied because it take the researchers to closer and understand individual's beliefs and perspective in a subjective meaningful ways and generating rich information for deeper understandings of their experience (Lieber, 2009). While the secondary data were firstly accessed from recent journals, online resources and others, which were useful in informing the primary data collection process, and were also used to support the findings.

\subsection{Participants and Setting}

The sampling design for this study started with an identification of sampling units who work in the operational level of the ICT public listed companies in Thailand that have been installed or exercised because the worldwide ICT sector is changing radically, the change are driven by a combination of market, business and technological forces. Also customer awareness and knowledge is increasing, they want services that satisfy their unique needs and demand reliable service delivery at competitive price (Xevelonakis, 2005). Moreover, the ability of the company to investment in the Information Technology due to CRM is required a lot of time and money, about 80 percents of CRM sales goes to large corporations (Bergeron, 2002). Moreover, the study of Shin (2006) has shown his finding that CRM would have the real effects in the firm who face with final customers such as telecom, credit card and financial companies, since these firms are mostly listed in stock market. Moreover, the participants were selected from the CRM installed companies who have more than one year CRM experience in their organizations because they should be familiar with their job. Also return on investment study must be done at least a year after the CRM system has been implemented in the organization, this is necessary in order to have enough time to identify the true saving and costs (Ingevaldson, 2009).

Initially, non-probability sampling procedure is adapted by the judgment sample which the researchers actively select the most productive sample to answer the research questions. With the purposive, convenience and snowball technique, the researchers contacted to the 129 samples who work in the operational level of CRM installed companies via e-mail and telephone request for interview regarding to this study, while 30 persons or 23.26 percents give the permission to interview individually. All informants (17 females and 13 males) came from several departments which are 7 from MIS department, 5 from marketing department, 4 from sale department, 4 from engineer department and 10 from customer service department of CRM installed companies. The participants also came from the various size of the CRM installed companies which range from less than 100 employees to more than 500 employees 
in their organizations. Moreover, 16 of informants are working related to the CRM system in their organization for 1-2 year, 8 of informants has 2-5 years of CRM experiences while 6 of informants has more than 5 year CRM experiences.

The researchers believe all the participants selected interviewees were knowledgeable, highly experienced and able to share their perspective toward the CRM practice. As a result, the selected techniques were considered to be useful and suitable for empirical study.

\subsection{Data Collection and Analysis Method}

Each interview took around 30-40 which vary from the availability of the informants at the interviewee's organization. The semi-structured survey questionnaires which were not frame into any particular model; but the interviewees were interacted and questioned within the scope of this study. The interviewed guideline had been prepared proved by the thesis advisor before the interview took place in order to make appropriate questions for the target groups. Also the interviews are designed by the researchers to direct both the content and focus of the interview. By asking specifically worded questions in a predetermined order, the researchers ensure a certain level of consistency when conducting the interviews. The interviewees were encouraged to share the opinions and perspective towards a CRM practice of their work environment and organization. When the researchers having interview with participants, the interesting quotes from the participants were recorded and transcribed by the researchers in order to highlight the important and different factors toward their perspective toward CRM practice. In order to ensure the validity of transcribe and understanding of the researcher, member-checking method (Lincoln \& Guba, 1985) was conducted with all informants by e-mail in order to corroborate findings of each informants and make sure the researchers representing their idea accurately. Then the researchers looked for common meaning and identified the themes that were evident in the data by grouping common statements and ideas. Moreover, the researchers also used the data form journals and notes from interview to interpret data according to this study.

\subsection{Result}

The overall result of interviews with the 30 operational level employees in CRM practice companies have shown that a clear vision of management toward the Customer Relationship Management System, Organization's perception and Employee's perception toward the benefit and important of Customer Relationship Management System (CRM Mindset) and level of co-operate within organization to use the Customer Relationship Management System (Employee buy-in) are the most important factors to the success of CRM practice in their operational level perspective. If the researcher classified the informants into 5 main groups according to the department which are MIS, Sale, Engineer, Marketing and Customer service department. The result will have a slightly different. While the participants from Sale, MIS, Customer support and Marketing department believe in a clear management vision toward the CRM system is the most important factor to CRM success, but the participants from Engineer department does not see any important of the management vision. On the other hand, the participants from Sale, MIS, Engineers and Marketing department believes in the support from management in term of tangible and intangible resources to support 
Customer Relationship Management System (Management Support), while the participants from customer service department are not. Moreover, the organization's perception and employee's perception toward the benefit and important of Customer Relationship Management System (CRM Mindset) is only the factor that conforming the managerial perspective toward the success of CRM practice

\section{Findings}

The result of the study is very interesting while the managerial level believes IT and Business culture gap, computer self-efficacy, CRM system utilization and organization's CRM mindset are the most important factors to the success of the CRM practice. In contrast, IT and Business culture gap and CRM evaluation process seem to be the less important factors and far distinct in the operation level perspective. In contrast, the operational level employees believe in a clear management vision, organization's CRM mindset, and employee buy-in are the most important factor. Thus, the perspective of managerial and operational level towards the CRM influential factor is likely to differ according to the job title, roles in organization (Palanisamy et al., 2010) and style which influence to the organization performance (Richardson and Foong, 2004). But the success of the CRM practice has to be initiated by the management top down (Xevelonakis, 2005). Therefore, the researchers have concluded that the important factors should come from the CRM common understanding of both managerial level and operation level as shown in Fig. 1 and the following factors:

Firstly, the managerial level should have clear vision regarding the CRM implementation and support to CRM in order to encourage the organization to have a positive CRM mindset which is a perception toward the benefit and important of Customer Relationship Management System. From many studies we can concluded that there is no single best way to secure level of top management sponsorship and support, but if it is absent, the risk of failure in CRM project increases significantly (William, 2006). The positive impact not only comes when you have only executive commitment, but also willingness to change behaviors and people with skill to actually use the technologies the right way (Neuborne, 2005). Also, if the organization would like to obtain the full benefits from complex technology, organizations should consider behavioral training that focus on the development of new job practices (Sahut \& Jegham, 2008). Training is an essential and intelligent way of educating and motivating staff and the commercial benefits to a business operation are indisputable and should focus on the customer satisfaction and retention (Richardson, 2009). It gives the employees to have more information on the change in business environment which are business process, policies rules, regulation and objective (Rootman et al, 2008), also achieve goals and realize mutually beneficial (Ingevaldson, 2009). The benefit of comprehensive training to employee is not only increased productivity and reduced cost, but also increased employee's skill and knowledge which they can realize to the business benefits, the important of CRM practice and customer satisfaction (Kilkelly, 2008).

Secondly, the operational level should focus in the level of co-operate within organization and positive perception to CRM practice in their organization. Both formal and informal communication can also use as a main key to transmitting and shaping successful culture 
management in the company (Lazidou, 2008). An effective communication is necessary to achieve the desired level of operational excellence and motivate person, it have to understood accurately by others, achieve the message's intended effect and ethical (Beebe \& Darling, 2007).

Thirdly, the CRM practice organization should utilize their CRM in place system in term of level of information sharing, data security and system performance, together with a change their business to support CRM system. While the support of CRM processes by the effective application of customer information lead to significant performance improvement, improve quality, shorten time efforts and cost saving (Salomann et al, 2006). The finding from the quantitative analysis of 821 questionnaires and qualitative study of 20 companies managers and employees conducted by Rahimi and Berman (2009) shows that the ease of CRM system management and user-friendly system are play a significant role for the success of the CRM utilization, but if the certain criteria which are customer-oriented organization, management support and implemented modules, employee resistance, flexibility in adopting work processes and perceived CRM benefit of CRM's user are not involved, it will increase the probability of failure in CRM. The critical success for measure IT utilization in the organization also needs support by the management because the utilization measurement require the information from the entire organization, with tangible goals and collected the information from company's officer, IT service department and project management (Cleary, 2008).As the CRM system can also greatly improve the internal process integration by sharing customer information across department (Raisinghani et al, 2005) So, it is a critical to understand the existing inefficiencies, waste and failure points in order to improve the business process (Furterer, 2009).

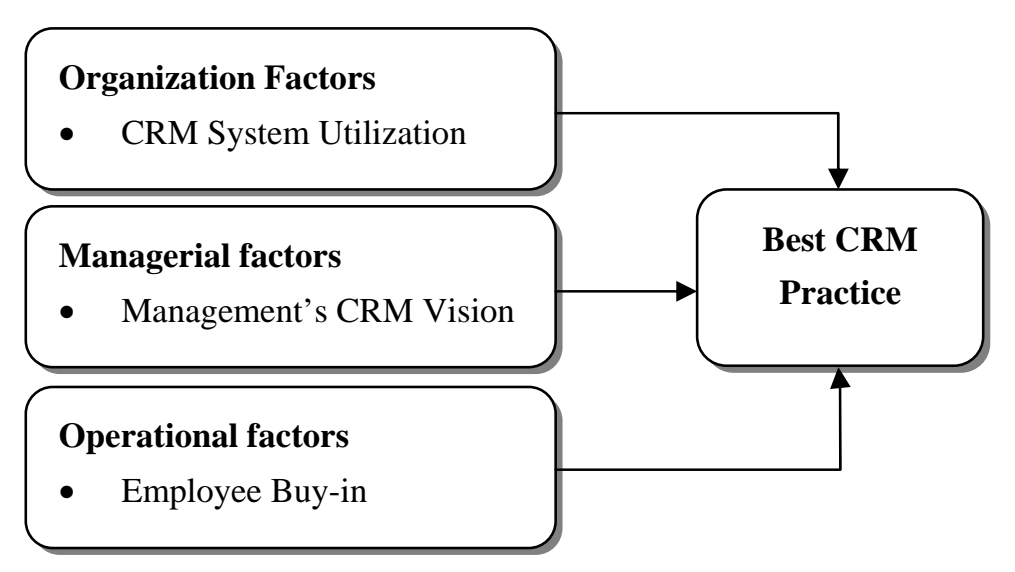

Figure 1. CRM Best Practice Model

\section{Conclusion}

Since the managerial and operational has a different perspective toward CRM in their organization, therefore in order to close this gap organizations should focus more on communication within organization in order to spread clear and concise information, together 
with a support to each individual's requirement, training to support and shape the mindset both for managerial and operational level, thus it will likely to improve the success rate of CRM practice and effective resource management (Rahman et al, 2010)

On the other hand, it is clear that this study was somewhat biased in terms of obtaining access to the targeted samples for in-depth interview due to the policies to share information to outsider. Also it took a long time to contact the participants and follow up for the permission to interview. For the further study, the researcher looking forward to have quantitative research in Information and Communication (ICT) public listed companies in Thailand in order to concrete the conceptual frame study and highlight the most important success factor to CRM practice, we use ICT sector as a model to study, the researcher thus it will able to apply for other sector who already installed CRM in their organization.

\section{References}

Aleric, D. (2007). Impact of CRM on the competitiveness level of ICT services in Croatian Service Providers. 19(1), 43.

Arunthari, S. (2005). Information Technology adoption by companies in Thailand: a study of Enterprise Resource Planning System usage. (Doctoral dissertation, University of Wollongong, 2005. Retrieved August 9, 2009, from http://ro.uow.edu.au/theses/338

Beebe, S. \& Darling, J. (2007).Effective Entrepreneurial Communication in Organization Development: Achieving Excellence Based on Leadership Strategies and Values. Organization Development Journal, 25(1), 76-93.

Bergeron, B. (2002). Essentials of CRM: A Guide to Customer Relationship Management. 1(1), 2. WILEY ISBN: 0-471-20603-2

Bhatt, G.D. \& Emdad, A.F. (2010). An empirical examination of the relationship between information technology (IT) infrastructure, customer focus, and business advantages. Journal of Systems and Information Technology, 12 (1), 4-16. doi: 10.1108/13287261011032625

Boulding, W., Staelin, R., Ehret, M., \& Johnston, W. (2005). A Customer Relationship Management Roadmap: What Is Known, Potential Pitfalls, and Where to Go. Journal of Marketing, 69(4), 155-166. doi:10.1509/jmkg.2005.69.4.155.

Bull, C. \& Adam, A. (2010). Customer Relationship Management Information Systems (CRM-IS) and the realization of moral agency. Journal of Information, Communication \& Ethics in Society, 8(2), 164-177.

Chahal, H. (2010). Two component customer relationship management model for health care services. Managing Service Quality, 20(4), 343-365.

Chang, K.C., Lie, T. \& Fan, M.L. (2010). The impact of organizational intervention on system usage extent. Industrial Management \& Data System, 110(4), 532-549.

Cleary, R. (2008). IT Measures That Matter. InformationWeek, (1184), 53-54,56. 
Dickie, J. (2009). 2009-Era Sales Needs 2009-Era CRM. Customer Relationship Management, 13(3), 8.

Doom, C., Milis, K., Poelmans, S. and Bloemen E. (2010). Critacal success factor for ERP implementations in Belgium SMEs. Journal of Enterprise Information Management, 23(3), 378-406.

Elmuti, D., Jia, H., \& Gray, D. (2009). Customer relationship management strategic application and organizational effectiveness: an empirical investigation. Journal of Strategic Marketing, 17(1), 75-96. doi:10.1080/09652540802619301.

Furterer, S.. (2009). Secure operational excellence. Industrial Engineer, 41(4), 43-47.

Glesne, C. (2006). Becoming qualitative researchers (3rd). Boston: Pearson Education, Inc.

Goldenberg, B. (2010). Assessing Your CRM Situation. CRM Magazine, 14(1), 10.

Greenberg, P. (2010). The impact of CRM 2.0 on customer insight. Journal of Business \& Industrial Marketing, 25(6), 410-419.

Ifinedo, P. (2008). Impacts of business vision, top management support, and external expertise on ERP success. Business Process Management Journal, 14(4), 551-568.

Ingevaldson, P. (2009). Dazzle Your CEO With Hard Facts. Computerworld, 43(22), 40.

Kimiloglu, H. \& Zarali, H. (2009). What signifies success in e-CRM? Marketing Intelligence \& Planning, 27(2), 246-267.

Kilkelly, E. (2008). IT training's impact on the bottom line. Training Journal, 47-51

Lambert, D.M. (2010). Customer Relationship Management as a business process. Journal of Business \& Industrial Marketing, 25(1), 4-17.

Lazidou, D.. (2008). Three Ways to Measure Your Corporate Culture. Strategic Communication Management, 12(3), 10.

Lieber, E. (2009). Mixing Qualitative and Quantitative Mehod: Insight into Design and Analysis Issue. (Lithuanian). Journal of Ethnographic \& Qualitative Research, 3(4), 218-227.

Limsarun, T. \& Anurit, P. The Customer Relationship Management practice of Information and Communication Technology public listed companies in Thailand. Journal of Alternative Perspective of Social Sciences, 2(Special Issue 2), 54-83.

Lincoln, Y. S., \& Guba, E. G. (1985). Naturalistic inquiry. Beverly Hills, CA: Sage Publications, Inc.

Lo, A.S., Stalcup, L.D. \& Lee A. (2010). Customer Relationship Management for hotels in Hong Kong. International Journal of Contemporary Hospitality Management, 22(2), 139-159. 
Lorenzon, A. \& Pilotti, L. (2008). The Role of Social and Cultural Contexts for the Implementation of CRM Projects. ICFAI Journal of Knowledge Management, 6(6), 79-96. Retrieved from Business Source Complete database.

Mukerjee, K., \& Singh, K. (2009). CRM: A Strategic Approach. ICFAI Journal of Management Research, 8(2), 65-82.

National Statistical office of Thailand (2007). Information and Communication Technology survey (Establishment). Retrieved September 30, 2010, from http://service.nso.go.th/nso/nso_center/project/search_center/23project-th.

Nguyen, T., Sherif, J. \& Newby, M. (2007). Strategies for successful CRM implementation. Information Management \& Computer Security, 15(2), 102-115.

Neuborne, E. (2005). A Second Act for CRM. Inc, 27(3), 40.

Palanisamy, R., Verville, J., Bernadas, C. \& Taskin, N. (2010). An empirical study on the influences on the acquisition of enterprise software decisions: A practitioner's perspective. Journal of Enterprise Information Management, 23(5), 610-639.

Palsinghtoor, T. (2009). Creating competitive edge through improved customer relationship management. Business Strategy Series, 10(1), 55-60.

Pedron, C., \& Saccol, A. (2009). What Lie behind the Concept of Customer Relationship Management? Discussing the Essence of CRM through a Phenomenological Approach. Brazilian Administration Review (BAR), 6(1), 34-49.

Rahimi, I., \& Berman, U. (2009). Building a CSF framework for CRM implementation. Journal of Database Marketing \& Customer Strategy Management, 16(4), 253-265. doi:10.1057/dbm.2009.29.

Rahman, M.N.A., N.K. Khamis, R.M. Zain, B.M. Deros and W.H.W. Mahmood, 2010. Implementation of 5S Practices in the Manufacturing Companies: A Case Study. Am. J. Applied Sci., 7: 1182-1189. DOI: 10.3844/.2010.1182.1189

Raisinghani, M., Tan, E., Untama, J.,Weiershaus, H. \& et al. (2005). CRM Systems in German Hospitals: Illustrations of Issues \& Trends. Journal of Cases on Information Technology, 1-26.

Raman, P., Wittmann, C., \& Rauseo, N. (2006). LEVERAGING CRM FOR SALES: The Role of Organizational Capability in Successful CRM Implementation. Journal of Personal Selling \& Sales Management, 26(1), 39-53

Ranjan, J. \& Bhatnagar, V. (2009). Principles for successful aCRM in Organizations. Direct Marketing: An International Journal, 2(4), 239-247.

Richardson, S. and Y.P. Foong, 2004. Culture and Managerial Styles: A Study of Potential Managers in Malaysia. Am. J. Applied Sci., 1: 279-283. DOI: 10.3844/.2004.279.283 


\section{Macrothink}

Journal of Management Research

ISSN 1941-899X

2011, Vol. 3, No. 1: E2

Richardson, M. (2009). Good Staff Training Leads To Customer Satisfaction. Caterer \& Hotelkeeper, 199(4583), 36

Rootman, C., Tait, M., \& Bosch, J.. (2008). Variables influencing the customer relationship management of banks. Journal of Financial Services Marketing: Special Issue: Strategic Developments in Financial Services, 13(1), 52-62.

Sahut, J., \& Jegham, M. (2008). ICT acceptation : The case of CRM project. Gestion 2000, 25(2), 213-221.

Salomann, H., Dous, M., Kolbe, L., \& Brenner, W. (2006). Advancing CRM Initiatives with Knowledge Management. Journal of Information Science \& Technology, 3(2), 23-44.

Shin, I. (2006). Adoption of Enterprise Application Software and Firm Performance. Small Business Economics, 26(3), 241-256. doi:10.1007/s11187-005-0215-9.

Shum, P., Bove, L. \& Auh, S. (2008). Employees' affective commitment to change: The key to success CRM implementation. European Journal of Marketing, 42(11/12), 1346-1371.

Skrinja, R., Vuksic,V.B. \& Stemberger, M.I. (2008). The impact of business process orientation on financial and non-financial performance. Business Process Management Journal, 14(5), 738-754.

Valsecchi, M., Renga, F.M., Rangone, A. (2007). Mobile customer relationship management: an exploratory analysis of Italian applications. Business Process Management Journal, 13(6), 755-770.

Ward, P. (2007). Not Your Father's CRM. Ten Reasons More Law Firms Choose Customer Relationship Management Systems. Of Counsel, 26(11), 12-15.

William, B. (2006). The ABCs Of CRM Success. Optimize, 5(1), 57-59,10.

Xevelonakis, E. (2005). Developing retention strategies based on customer profitability in telecommunications: An empirical study. Journal of Database Marketing \& Customer Strategy Management, 12(3), 226-242.

Yi-Te, W. (2010). Applying the Strategic Approach to Assess Customer Relationship Management. International Journal of Organizational Innovation, 2(3), 186-205.

Zineldin, M. (2006). The royalty of loyalty; CRM, quality and retention. Journal of Consumer Marketing, 23(7), 430-437. 